\title{
Global Longitudinal Strain Predicts Poor Functional Capacity in Patients with Systolic Heart Failure
}

\author{
Rafael José Coelho Maia, ${ }^{1}$ Simone Cristina Soares Brandão, ${ }^{1}$ Jéssica Leite, ${ }^{2 \oplus}$ Giordano Bruno Parente, ${ }^{3}$ \\ Filipe Pinheiro, ${ }^{2}$ Bruna Thays Santana Araújo, ${ }^{2 \bullet}$ Maria Inês Remígio Aguiar, ${ }^{1}$ Sílvia Marinho Martins, ${ }^{4}$ \\ Daniella Cunha Brandão, ${ }^{2}$ Armele Dornelas de Andrade ${ }^{1}$ \\ Universidade Federal de Pernambuco - Ciências da Saúde, ${ }^{1}$ Recife, PE - Brazil \\ Universidade Federal de Pernambuco - Fisioterapia, ${ }^{2}$ Recife, PE - Brazil \\ Hospital Agamenon Magalhaes - Cardiologia, ${ }^{3}$ Recife, PE - Brazil \\ Pronto Socorro Cardiológico de Pernambuco (PROCAPE) - Ambulatório de Doença de Chagas e Insuficiência Cardíaca, ${ }^{4}$ Recife, PE - Brazil
}

\begin{abstract}
Background: Left ventricular global longitudinal strain value (GLS) can predict functional capacity in patients with preserved left ventricular ejection fraction (LVEF) heart failure (HF) and to assess prognosis in reduced LVEF HF.
\end{abstract}

Objetive: Correlate GLS with parameters of Cardiopulmonary Exercise Test (CPET) and to assess if they could predict systolic HF patients that are more appropriated to be referred to heart transplantation according to CPET criteria.

Methods: Systolic HF patients with LVEF < 45\%, NYHA functional class II and III, underwent prospectively CPET and echocardiography with strain analysis. LVEF and GLS were correlated with the following CPET variables: maxVO $_{2^{\prime}}$ VE/VCO slope, heart rate reduction during the first minute of recovery (HRR) and time needed to reduce maxVO in $50 \%$ after physical exercise $\left(\mathrm{T}_{1 / 2} \mathrm{VO}_{2}\right)$. ROC curve analysis of GLS to predict $\mathrm{VO}_{2}<14 \mathrm{~mL} / \mathrm{kg} / \mathrm{min}$ and $\mathrm{VE} / \mathrm{VCO}_{2}$ slope $>35$ (heart transplantation's criteria) was performed.

Results: Twenty six patients were selected (age, $47 \pm 12$ years, $58 \%$ men, mean LVEF $=28 \pm 8 \%$ ). LVEF correlated only with maxVO ${ }_{2}$ and $\mathrm{T}_{1 / 2} \mathrm{VO}_{2}$. GLS correlated to all CPET variables $\left(\mathrm{maxVO}_{2}: r=0.671, \mathrm{p}=0.001 ; \mathrm{VE} / \mathrm{VCO}_{2}\right.$ slope: $r=-0.513, p=0.007$; HRR: $r=0.466, p=0.016$, and $\left.T_{1 / 2} V_{2}: r=-0.696, p=0.001\right)$. GLS area under the ROC curve to predict heart transplantation's criteria was 0.88 (sensitivity $75 \%$, specificity $83 \%$ ) for a cut-off value of $-5.7 \%, p=0.03$.

Conclusion: GLS was significantly associated with all functional CPET parameters. It could classify HF patients according to the functional capacity and may stratify which patients have a poor prognosis and therefore to deserve more differentiated treatment, such as heart transplantation. (Arq Bras Cardiol. 2019; 113(2):188-194)

Keywords: Heart Failure;Longitudinal Strain; Torsion,Mechanical; Torsion Abnormality; Ventricular Dysfunction, Left; Echocardiography, Doppler/methods.

\section{Introduction}

The cardiopulmonary exercise test (CPET) is the gold standard method for assessing functional capacity in patients with heart failure (HF). It is able to measure during exercise, maximum myocardial oxygen consumption $\left(\max \mathrm{VO}_{2}\right)$, $\mathrm{CO}_{2}$ production, ratio minute ventilation/carbon dioxide production $\mathrm{VE} / \mathrm{VCO}_{2}$ slope, $\mathrm{VO}_{2}$ recovery kinetics after physical exertion $\left(\mathrm{T}_{1 / 2} \mathrm{VO}_{2}\right)$, stratify cardiovascular risk and predict mortality and hospitalization by these parameters, for example, $\mathrm{VO}_{2}$ values $<14 \mathrm{~mL} / \mathrm{kg} / \mathrm{min}$ and $\mathrm{VE} / \mathrm{VCO}_{2}$ slope $>35$ that are criteria for heart transplantation. ${ }^{1-4}$

Mailing Address: Simone Cristina Soares Brandão •

Universidade Federal de Pernambuco - Pós-Graduação em Ciências da

Saúde - Av. Professor Moraes Rego, 1235. Postal Code 50670-901, Cidade

Universitária, Recife, PE - Brazil

E-mail: sbrandaonuclearufpe@gmail.com

Manuscript received July 19, 2018, revised manuscript October 28, 2018 accepted November 14, 2018

DOI: $10.5935 / a b c .20190119$
Furthermore, CPET evaluates the presence of dysautonomia, by measuring the reduction in heart rate within the first minute after exercise (HRR), ${ }^{5,6}$ which is directly related to cardiovascular outcome..$^{7-9}$

However, in patients with systolic HF, the reduction of myocardial contractility, measured mainly by echocardiography through the left ventricular ejection fraction (LVEF), is the main parameter used to classify the myocardial damage degree, ${ }^{10}$ although its value is little associated with the clinical symptoms and functional capacity of these patients. ${ }^{1,10}$ The strain analysis is a newer echocardiography tool and has demonstrated more effective in assessing global derangement of the left ventricle (LV) than the LVEF measurement. ${ }^{10}$

Recent studies show that the left ventricular global longitudinal strain value (GLS) can predict functional capacity in patients with HF and preserved LVEF, ${ }^{11}$ and assess prognosis in HF with reduced LVEF when compared with life expectancy scores. ${ }^{12}$ Additionally, this technique evaluates the degree of myocardial deformation and it seems to predict the degree of regional and global LV fibrosis. ${ }^{13}$ However, there are no studies comparing the GLS with CPET parameters 
in patients with systolic HF. The aim of this study was to correlate GLS value with functional parameters of CPET and to assess if GLS could predict systolic HF patients that were more appropriated to be referred to heart transplantation according to CPET criteria.

\section{Methods}

This is an observational, prospective cross-sectional study, guided by the recommendations of the STROBE Statement. ${ }^{14}$ This study was approved by the Ethics and Research Committee of our Institution under number 1507992.

The study population consisted of adults (21-65 years), both sexes, diagnosed with HF in functional class II and III by the New York Heart Association (NYHA), sedentary, with systolic dysfunction (LVEF $<45 \%$ ) assessed by transthoracic echocardiography performed until one month before they had been referred for cardiopulmonary program and recruited for this study. Data were collected between January, 2015 and March, 2016.

Exclusion criteria were: deformity in the face to prevent the coupling of the CPET mask, orthopedic and neurological diseases that could preclude the execution of CPET, psychological problems restricting them to respond to the questionnaire, functional class IV HF or hospitalization due to cardiac decompensation in the last three months, unstable angina, myocardial infarction or cardiac surgery up to three months before the study; forced expiratory volume on the first one second/forced vital capacity $<70 \%$ of predicted characterizing obstructive respiratory disorder.

To ensure standardization, a single examiner performed the exams. None of them had access to the patients' other evaluations results. The researchers responsible for data collection were not responsible for carrying out the examinations, thus ensuring the blinding of the study.

\section{Cardiopulmonary exercise test}

All patients in the study underwent CPET by the method ramp on a treadmill (Centurium 300, Micromed, Brazil) through ErgoPC Elite ${ }^{\circledR}$ software associated with the electrocardiogram (Micromed, Brazil) with 12 channels. Respiratory variables were evaluated by a gas analyzer (Cortex - Metalyzer II, Germany) and obtained in conditions of standard temperature, pressure and dry (STPD), breath-by-breath, with the patient breathing in a face mask without leaks during exercise. During the test, functional capacity, maxVO ${ }_{2}$ measured in METs, the maximum VE/VCO, $\mathrm{VE} / \mathrm{VCO}_{2}$ slope, $\mathrm{T}_{1 / 2} \mathrm{VO}_{2}$ and HRR were evaluated.

\section{Echocardiography}

All echocardiograms were performed according to ASE. ${ }^{14}$ Patients underwent the two-dimensional echocardiography, using an ultrasound system Vivid I (GE Medical Systems, Horten, Norway) with a multifrequency transducer from 2.5 to $5 \mathrm{MHz}$.

After the echocardiogram, a strain analysis technique was performed using an echocardiogram analysis software (EchoPAC, GE Medical Systems, Horten, Norway, version
10.0). The images in the longitudinal sections were analyzed (4 chambers, 3 chambers and 2 chambers). ${ }^{15} \mathrm{~A}$ region of interest was applied automatically by the software and, if necessary, was adjusted manually. The strain analysis software performed the analysis. Patients were excluded when more than two segments were considered to have insufficient quality for monitoring by the analysis system. ${ }^{16}$

\section{Statistical analysis}

To calculate the sample, G*Power 3 software was used, ${ }^{17}$ in which we chose the post hoc option with $\alpha=0.05$ and two-tailed hypothesis. Thus, the two most important ergospirometric variables were chosen for the study population: $\mathrm{maxVO}_{2}$ and $\mathrm{VE} / \mathrm{VCO}_{2}$ slope. We found an effect size of $0.81\left(R^{2}=0.67\right)$ for the maxVO and $0.71\left(R^{2}=0.51\right)$ for the $\mathrm{VE} / \mathrm{VCO}_{2}$ slope. We observed for both variables a power of $99 \%$ with a total sample of 25 patients.

Patients were later divided into two groups according to values of $\operatorname{maxVO}_{2}$ and VE/VCO ${ }_{2}$ slope found to CPET: Group 1 - $\mathrm{maxVO}_{2}>14 \mathrm{~mL} / \mathrm{kg} / \mathrm{min}$ and/or VE $/ \mathrm{VCO}_{2}$ slope < 35; and Group $2-\mathrm{maxVO}_{2}<14 \mathrm{~mL} / \mathrm{kg} / \mathrm{min}$ and VE/ $/ \mathrm{VCO}_{2}$ slope $>35$ (Ila class indication criteria for heart transplantation). ${ }^{16}$

The data was presented by absolute and percentage frequencies for categorical variables; by the mean and standard deviation for parametric quantitative variables; and by median and interquartile range for non-parametric variables. Shapiro-Wilk test was applied to verify if the quantitative data were normals. For comparison of parametric variables, we used the Student t-test for independent samples and for non-parametric variables the Mann-Whitney test. To compare categorical variables, we used the chi-square non-parametric test.

In the second step, the correlation between the values of the GLS strain index with ergospirometric variables was performed by using the Pearson coefficient for parametric and Spearman variables for non-parametric variables. The Receiver Operating Characteristic (ROC) curve was performed to evaluate the GLS's ability to predict $\operatorname{maxVO}_{2}<14 \mathrm{~mL} / \mathrm{kg} / \mathrm{min}$ and $\mathrm{VE} / \mathrm{VCO}_{2}$ slope $>35$.

$P$ value inferior to 0.05 was considered statistically significant. Data were entered in an EXCEL spreadsheet and statistical software used for statistical calculations was the SPSS (Statistical Package for Social Sciences) version 23.

\section{Results}

During the study period, 39 patients with HF were referred to the cardiopulmonary rehabilitation program. Of these, 10 were not included because of a LVEF higher than $45 \%$, one patient for presenting inadequate acoustic window for subsequent analysis of the GLS and two patients due to arrhythmia. Therefore, 26 patients (mean age, $47 \pm 12$ years, $58 \%$ men) participated in this study, Table 1.

Regarding the CPET results the average maxVO $\mathrm{O}_{2}$ was $19.09 \pm 9,52 \mathrm{~mL} / \mathrm{kg} / \mathrm{min}$ and the $\mathrm{VE} / \mathrm{VCO}_{2}$ slope was $39.43 \pm 9.91$. The mean HRR and $\mathrm{T}_{1 / 2} \mathrm{VO}_{2}$ were respectively, $19.65 \pm 17.42 \mathrm{bpm}$ and $168.61 \pm 43.90 \mathrm{~s}$. By echocardiography, the mean LVEF was $28.0 \pm 8.6 \%$ and mean GLS index was $-7.5 \pm 3.92 \%$ for all studied patients, Table 1 . 
Table 1 - Characteristics of the study population

\begin{tabular}{|c|c|}
\hline Variable & $(n=26)$ \\
\hline Age (years), mean $\pm \mathrm{DP}$ & $47.31 \pm 12.71$ \\
\hline \multicolumn{2}{|l|}{ Gender: $\mathbf{n}(\%)$} \\
\hline Men & $15(57.7)$ \\
\hline Women & $11(42.3)$ \\
\hline BMI $\left(\mathrm{Kg} / \mathrm{m}^{2}\right):$ Mean $\pm \mathrm{DP}$ & $29.31 \pm 5.38$ \\
\hline \multicolumn{2}{|l|}{ Comorbidities: $n(\%)$} \\
\hline SAH & $20(77)$ \\
\hline $\mathrm{DM}$ & $15(61)$ \\
\hline \multicolumn{2}{|l|}{ HF Etiology: $\mathbf{n}(\%)$} \\
\hline Ischemic & $6(23)$ \\
\hline Hypertensive & $10(39)$ \\
\hline Myocarditis & $4(15)$ \\
\hline Chagas' Disease & $1(4)$ \\
\hline Idiopathic & $5(19)$ \\
\hline \multicolumn{2}{|l|}{ Medication: $\mathbf{n}(\%)$} \\
\hline ACEI/ARB & $23(88)$ \\
\hline Beta blocker & $26(100)$ \\
\hline Diuretics K-sparing & $22(84)$ \\
\hline $\operatorname{LVEF}(\%)($ mean $\pm \mathrm{DP})$ & $28,0 \pm 8.62$ \\
\hline Strain $(\%)($ mean $\pm D P)$ & $-7.5 \pm 3.92$ \\
\hline $\operatorname{maxVO}_{2}($ mean $\pm \mathrm{DP})$ & $19.09 \pm 9.52$ \\
\hline $\mathrm{VE} / \mathrm{VCO}_{2}$ slope $($ mean $\pm \mathrm{DP})$ & $39.43 \pm 9.91$ \\
\hline $\mathrm{HRR}(\mathrm{bpm})($ mean $\pm \mathrm{DP})$ & $19.65 \pm 17.42$ \\
\hline $\mathrm{T}_{1 / 2} \mathrm{VO}_{2}(\mathrm{~s})($ mean $\pm \mathrm{DP})$ & $168.61 \pm 43.90$ \\
\hline
\end{tabular}

BMI: body mass index; SAH: systemic arterial hypertension; DM: diabetes mellitus; ACEI/ARB: converting the angiotensin-converting enzyme inhibitor/angiotensin receptor blocker; LVEF: left ventricular ejection fraction; maxVO, maximal oxygen consumption; $V E / V \mathrm{O}_{2}$ slope: slope of the VE/NCO ${ }_{2}$ curve; HRR: heart rate recovery; $\mathrm{T}_{1 / 2} \mathrm{VO}_{2}$ : time to $\mathrm{VO}_{2}$ halving recovery.

\section{Correlation of CPET variables with LVEF and GLS measurements}

When comparing the CPET with LVEF data (Table 2), a positive correlation was observed only with maxVO $(r=0.585, p=0.02)$ and negative with $\mathrm{T}_{1 / 2} \mathrm{VO}_{2}(r=-0.530$; $\mathrm{p}=0.005)$. For the other variables, LVEF showed no correlation, Table 2.

The GLS showed significant correlation with all analysed CPET variables. This parameter was positively correlated with maxVO $\mathrm{V}_{2}$ and $\mathrm{HRR}$ and inversely with $\mathrm{VE} / \mathrm{VCO}_{2}$ slope and $\mathrm{T}_{1 / 2} \mathrm{VO}_{2}$, Table 2 and Figure 1.

Regarding $\mathrm{VO}_{2}$ group $>14 \mathrm{~mL} / \mathrm{kg} / \mathrm{min}$ and/or $\mathrm{VE} / \mathrm{VCO}$, slope $<35$ and $\mathrm{VO}_{2}$ group $<14 \mathrm{~mL} / \mathrm{kg} / \mathrm{min}$ and VE/VCO slope $>35$, there were no differences in clinical variables, comorbidities and medications used. However, echocardiographic variables showed differences, as shown in Table 3.
The area under the ROC curve (Figure 2) for the GLS index value as a predictor of poor functional capacity and worse prognosis was $0.88(95 \% \mathrm{Cl}=0.75$ to 1.00$)$, with a sensitivity of $75 \%$, specificity of $83 \%$, positive predictive value of $67 \%$, and negative predictive value of $88 \%$, for a cut-off GLS value of $-5.7 \%, p=0.03$.

\section{Discussion}

In this study, in patients with systolic HF referred for a cardiopulmonary rehabilitation program, the GLS was significantly associated with all functional CPET parameters. It seems to be more accurate than LVEF in classifying patients with HF according to the functional capacity and thus may stratify which patients have a poor prognosis and therefore to deserve more differentiated treatment, such as heart transplantation.

Previous studies have demonstrated that LVEF has no correlation with functional capacity. ${ }^{1,10}$ However, there is limited data on the association between exercise tolerance and the results of analysis by cardiac strain. This study showed that LVEF was associated with maxVO and $\mathrm{T}_{1 / 2} \mathrm{VO}_{2}$ however, showed no correlation with the other CPET variables. Whereas peak $\mathrm{VO}_{2}$ values and $\mathrm{VE} / \mathrm{VCO}$ slope are parameters which help in end-stage HF decision making ${ }^{4,16}$ and that in this study, the GLS value was correlated with all these variables, we could suggest that the GLS may have a prognostic significance in this group of patients. In addition, GLS correlation with maxVO $\mathrm{O}_{2}$ and $\mathrm{T}_{1 / 2} \mathrm{VO}_{2}$ was better than LVEF, thus demonstrating that the GLS is a more accurate tool.

Hasselberg et al., ${ }^{11}$ in their study that evaluated HF patients, either with normal or reduced LVEF, were able to show the importance of GLS as a predictor of exercise capacity in patients with preserved LVEF HF. ${ }^{11}$ However, these authors have failed to demonstrate this relationship in patients with reduced LVEF. In the present study, we observed this correlation between GLS and functional capacity. This may have occurred since our study evaluated patients in more advanced stages of cardiac dysfunction. The average GLS in our study was worse than the Hasselbach study. ${ }^{11}$

The $\mathrm{T}_{1 / 2} \mathrm{VO}_{2}$ has also proven an important tool for predicting outcomes. The longer the $\mathrm{VO}_{2}$ recovery time of HF patients after physical exercise, the worse the cardiovascular prognosis. ${ }^{18-21}$ Our study demonstrated that the GLS was able to determine patients that have delayed recovery of $\mathrm{VO}_{2}$. The lower the value of GLS, the greater the time required for the post-physical effort $\mathrm{VO}_{2}$ to be reduced to half, suggesting the hypothesis that the GLS could estimate the prognosis of the patient.

Another evidence that supports the prognostic importance of GLS was dysautonomia analysis. It is known that there is a relationship between HRR in the first minute after physical exercise with mortality. The cardiovascular prognosis appears to be independent of symptoms, the type of recovery protocol, LVEF, and severity of coronary lesions in coronary angiography. ${ }^{7-9,21,22}$ This study showed a direct relationship between the GLS value and HRR in the first minute after effort, with a less accentuated drop in heart rate in patients who had a lower GLS value. 


\section{Original Article}

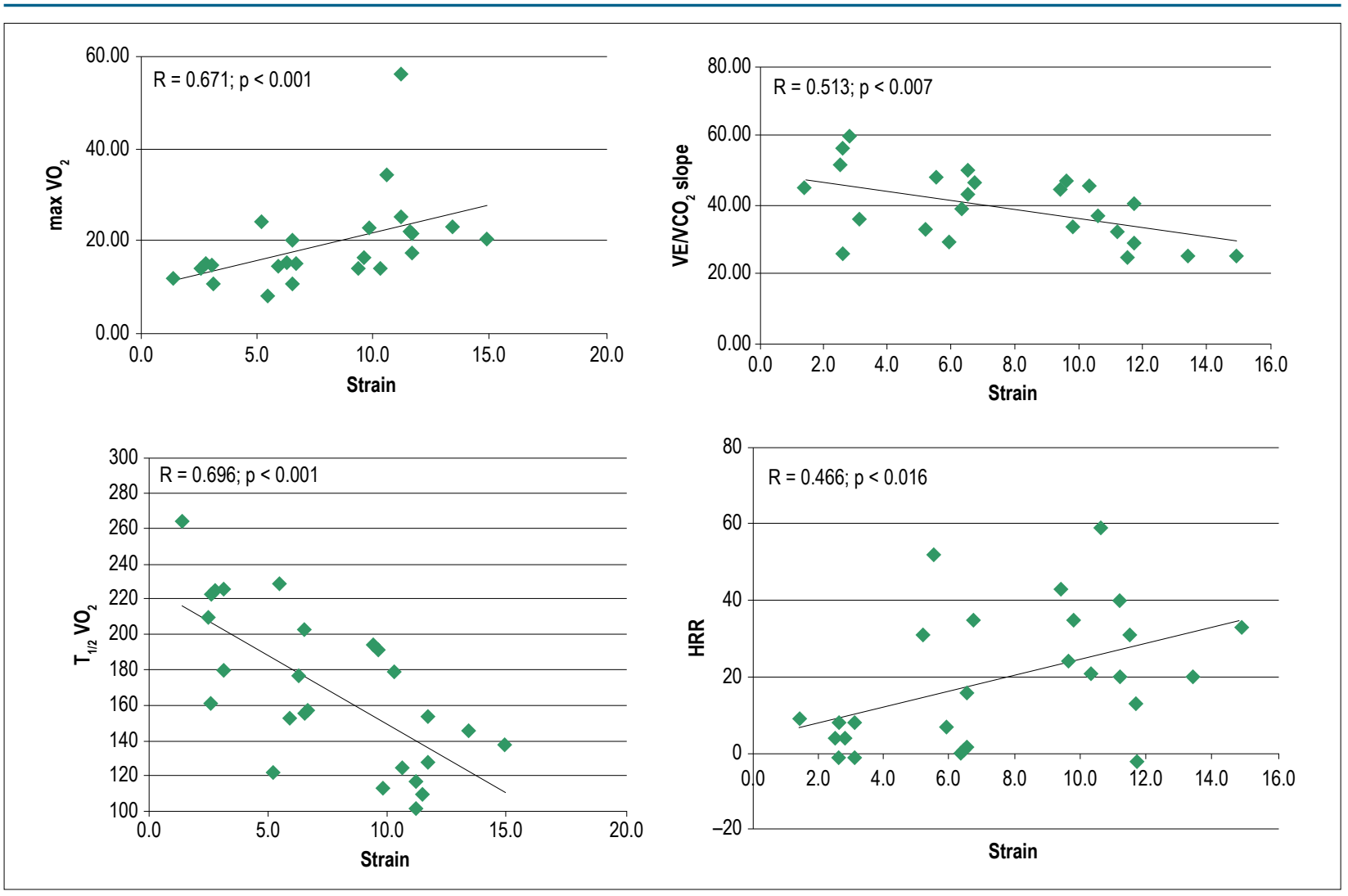

Figure 1 - Global longitudinal strain index (GLS) scatter plots compared to maxVO, $V E N C O_{2}$ slope, $H R R$, and $T_{112} V_{2}$. maxVO: maximal oxygen consumption; $\mathrm{VENCO}{ }_{2}$ slope: slope of the $\mathrm{VENCO}{ }_{2}$ curve; $\mathrm{HRR}$ : heart rate recovery; $\mathrm{T}_{1 / 2} \mathrm{VO}_{2}$ : time to $\mathrm{VO}_{2}$ halving recovery.

Table 2 - Correlation of numerical variables of Cardiopulmonary Exercise Test with left ventricular ejection fraction (LVEF) and global longitudinal strain index (GLS)

\begin{tabular}{lll}
\hline Variables & LVEF (p value) & GLS (p value) \\
\hline HRR-bpm & $0.288(0.154)^{(1)}$ & $0.466(0.016)^{*(1)}$ \\
maxVO $_{2}$ & $0.585(0.002)^{*(2)}$ & $0.671(<0.001)^{*(2)}$ \\
$\mathrm{VE}_{\mathrm{N} \mathrm{CO}_{2} \text { slope }}$ & $-0.330(0.100)^{(1)}$ & $-0.513(0.007)^{*(1)}$ \\
$\mathrm{T}_{1 / 2} \mathrm{VO}_{2}$ & $-0.530(0.005)^{*(1)}$ & $-0.696(<0.001)^{*(1)}$ \\
\hline
\end{tabular}

HRR: heart rate recovery; $T_{112} \mathrm{VO}_{2}$ : time to $\mathrm{VO}_{2}$ halving recovery; $\mathrm{VE} / \mathrm{VCO}_{2}$ slope: slope of the $\mathrm{VE} / \mathrm{VCO}_{2}$ curve; maxVO: maximal oxygen consumption. ${ }^{*} p<0,05$; (1) - Pearson coefficient; (2) - Spearman coefficient.

Cameli et al., ${ }^{13}$ evaluated patients with severe HF, with cardiac transplant indication, and, by histopathology of the heart after heart transplantation, found that no echocardiographic parameter, performed before heart transplant, was able to correlate with the presence of fibrosis except the GLS value. Therefore, a lower GLS value indicates that there is presence of more cardiac fibrosis, and consequently, there is less deformation and myocardium thickening, and relaxation and contractility is more defective. These changes entail low functional capacity and are responsible for worse prognosis. ${ }^{13}$ However, in that study, functional capacity was not assessed through an objective test, such as CPET.
Rangel et al. ${ }^{12}$ evaluated patients with LVEF less than $45 \%$ and demonstrated that the GLS value correlates with more advanced stages of the disease and is an independent predictor of life expectancy. ${ }^{12}$ That is, in patients with severe HF and similar LVEF, GLS was able to show which patients would present an unfavourable outcome. Our study showed that in patients with reduced LVEF, the lowest GLS value was correlated with CPET parameters that assess exercise tolerance and prognosis disease.

When rating the GLS cut-off in predicting poor prognosis, Rangel et al. ${ }^{12}$ used the Seattle HF model to assess the long-term survival, and it was shown that the best GLS cut-off point 


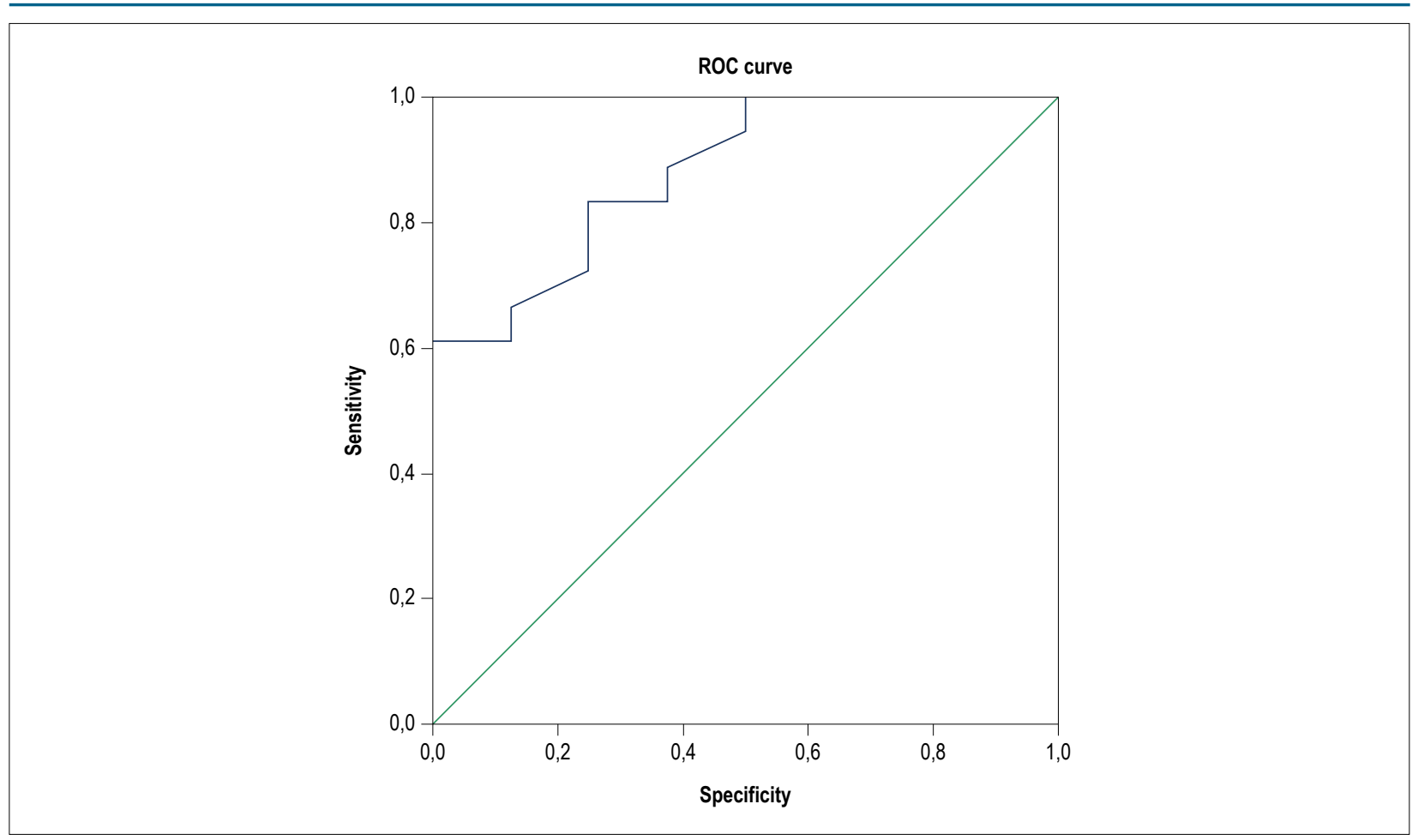

Figure 2 - ROC curve for evaluating the ability of the global longitudinal strain index (GLS) in predicting VO $<14 \mathrm{~mL} / \mathrm{kg} / \mathrm{min}$ and VENCO slope $>35$. Sensitivity of $75 \%$ and specificity of $83 \%$ for a GLS cut-off of $-5.7 \%, p=0.03$.

was $-9.5 \%$. Our study correlated the GLS value with CPET parameters and suggested a cut-off point of $-5.7 \%$ for GLS value, with sensitivity of $75 \%$ and specificity of $83 \%$ in predicting CPET heart transplantation's criteria.

\section{Study limitations}

Considering the small number of patients included in this study, our findings that the GLS showed a strong correlation with the CPET data and have been able to identify the patients who had ergospirometric criteria of worse prognosis, need to be proven through a study with a larger number of patients and of long-term monitoring, and thus determine the real power of GLS in the prognostic assessment and therapeutic setting in systolic HF.

\section{Conclusion}

In systolic HF patients, the GLS showed significant association with the main parameters of CPET and was able to classify patients with low functional capacity. Thus, GLS may be a more accurate parameter than LVEF in stratifying systolic HF patients. Moreover, it may play a role in helping to evaluate patients in the end stage of HF.

\section{Author contributions}

Conception and design of the research: Brandão SCS, Brandão DC, Leite J, Martins SM, Andrade AD; Acquisition of data: Maia RJC, Brandão DC, Leite J, Pinheiro F, Araújo BTS, Aguiar MIR, Martins SM; Analysis and interpretation of the data: Brandão SCS, Brandão DC, Leite J, Parente GB,
Pinheiro F, Araújo BTS, Aguiar MIR, Andrade AD; Statistical analysis: Brandão SCS, Parente GB; Writing of the manuscript: Maia RJC, Brandão SCS, Leite J; Critical revision of the manuscript for intellectual content: Brandão SCS, Brandão DC, Andrade AD.

\section{Potential Conflict of Interest}

No potential conflict of interest relevant to this article was reported.

\section{Sources of Funding}

This study was funded by FACEPE APQ-0154-4.08/15; FACEPE IBPG-0450-4.08/17; National Council for Scientific and Technological Development (CNPq) 432865/2016-0 and Coordination for the Improvement of Higher Education Personnel (CAPES).

\section{Study Association}

This article is part of the thesis of master submitted by Rafael José Coelho Maia, from Universidade Federal de Pernambuco.

\section{Ethics approval and consent to participate}

This study was approved by the Ethics Committee of the Universidade Federal de Pernambuco under the protocol number 38572614.1.000.5208. All the procedures in this study were in accordance with the 1975 Helsinki Declaration, updated in 2013. Informed consent was obtained from all participants included in the study. 


\section{Original Article}

Table 3 - Comparison between Group $1-\mathrm{VO}_{2} \max >14 \mathrm{~mL} / \mathrm{kg} / \mathrm{min}$ and $/$ or VE/VCO 2 slope $<35$ and Group $2-\operatorname{maxVO}<14 \mathrm{~mL} / \mathrm{kg} / \mathrm{min}$ and $\mathrm{VE} / \mathrm{VCO}_{2}$ slope $>35$

\begin{tabular}{|c|c|c|c|}
\hline Variables & $\begin{array}{c}\mathrm{VO}_{2}>14 \mathrm{~mL} / \mathrm{kg} / \mathrm{min} \text { and } / \text { or VE } / \mathrm{VCO}_{2} \\
\text { slope }<35(\mathrm{n}=18)\end{array}$ & $\begin{array}{c}\mathrm{VO}_{2}<14 \mathrm{~mL} / \mathrm{kg} / \mathrm{min} \text { and } \mathrm{VE} / \mathrm{VCO}_{2} \\
\text { slope }>35(\mathrm{n}=8)\end{array}$ & $\mathrm{p}$ value \\
\hline Age (years): Mean $\pm \mathrm{DP}$ & $45.7 \pm 13.7$ & $51.0 \pm 10.0$ & $0.334^{(1)}$ \\
\hline \multicolumn{4}{|l|}{ Gender: $\mathrm{n}(\%)$} \\
\hline Men & $11(61.1)$ & $4(50.0)$ & $0.683^{(2)}$ \\
\hline Women & $7(38.9)$ & $4(50.0)$ & \\
\hline BMI $\left(\mathrm{Kg} / \mathrm{m}^{2}\right):$ Mean $\pm \mathrm{DP}$ & $29.4 \pm 6.1$ & $29.0 \pm 3.7$ & $0.849^{(3)}$ \\
\hline \multicolumn{4}{|l|}{ Comorbidities: n (\%) } \\
\hline SAH & $13(72.2)$ & $7(87.5)$ & $0.628^{(2)}$ \\
\hline DM & $10(55.6)$ & $6(75.0)$ & $0.420^{(2)}$ \\
\hline \multicolumn{4}{|l|}{ HF Etiology: $n(\%)$} \\
\hline Ischemic & $5(27.8)$ & $1(12.5)$ & $0.628^{(2)}$ \\
\hline Hypertensive & $7(38.9)$ & $3(37.5)$ & $1.000^{(2)}$ \\
\hline Myocarditis & $3(16.7)$ & $1(12.5)$ & $1.000^{(2)}$ \\
\hline Chagas' disease & $1(5.6)$ & $0(0.0)$ & $1.000^{(2)}$ \\
\hline Idiopatic & $2(11.1)$ & $3(37.5)$ & $0.281^{(2)}$ \\
\hline \multicolumn{4}{|l|}{ Medication: $n(\%)$} \\
\hline ACEI/ARB & $16(88.9)$ & $7(87.5)$ & $1.000^{(2)}$ \\
\hline Beta blocker & $18(100.0)$ & $8(100.0)$ & $1.000^{(2)}$ \\
\hline Diuretics K-sparing & $15(83.3)$ & $7(87.5)$ & $1.000^{(2)}$ \\
\hline $\operatorname{LVEF}(\%)($ mean $\pm \mathrm{DP})$ & $30.6 \pm 8.5$ & $22.4 \pm 6.0$ & $0.021^{(1)}$ \\
\hline Strain $(\%)($ mean $\pm D P)$ & $8.6 \pm 3.8$ & $5.2 \pm 3.3$ & $0.037^{(3)}$ \\
\hline $\operatorname{maxVO}_{2}($ mean $\pm \mathrm{DP})$ & $22.1 \pm 10.0$ & $12.4 \pm 3.3$ & $0.014^{(3)}$ \\
\hline $\mathrm{VE} / \mathrm{VCO}_{2}$ slope $($ mean $\pm \mathrm{DP})$ & $35.8 \pm 9.3$ & $47.5 \pm 5.8$ & $0.003^{(1)}$ \\
\hline $\mathrm{HRR}(\mathrm{bpm})($ mean $\pm \mathrm{DP})$ & $20.2 \pm 17.2$ & $18.4 \pm 19.0$ & $0.004^{(3)}$ \\
\hline $\mathrm{T}_{1 / 2} \mathrm{VO}_{2}(\mathrm{~s})($ mean $\pm \mathrm{DP})$ & $147.5 \pm 32.1$ & $216.1 \pm 25.7$ & $<0.001^{(1)}$ \\
\hline
\end{tabular}

BMI: body mass index; SAH: hypertension; DM: diabetes mellitus; ACEI/ARB: converting the angiotensin-converting enzyme inhibitor/angiotensin receptor blocker; LVEF: left ventricular ejection fraction; maxVO; : maximal oxygen consumption; $V E / V_{2} O_{2}$ slope: slope of the VENCO ${ }_{2}$ curve; HRR: heart rate recovery; $T_{112} V O_{2}$ : time to $\mathrm{VO}_{2}$ halving recovery. (1) - Student t test; (2) - Mann-Whitney test; (3) - chi-square test.

\section{References}

1. Arena R, Guazzi M, Cahalin LP, Myers J. Revisiting cardiopulmonary exercise testing applications in heart failure: aligning evidence with clinical practice. Exerc Sport Sci Rev. 2014;42(4):153-60.

2. Arena R, Myers J, Aslam SS, Varughese EB, Peberdy MA. Peak VO2 and VE/ VCO2 slope in patients with heart failure: a prognostic comparison. Am Heart J. 2004;147(2):354-60.

3. Guazzi M, Adams V, Conraads V, Halle M, Mezzani A, Vanhees L, et al. EACPR/AHA Scientific Statement. Clinical recommendations for cardiopulmonary exercise testing data assessment in specific patient populations. Circulation. 2012;126(18):2261-74.

4. Parikh MN, Lund LH, Goda A, Mancini D. Usefulness of peak exercise oxygen consumption and the heart failure survival score to predict survival in patients $>65$ years of age with heart failure. Am J Cardiol. 2009;103(7):998-1002.
5. Arena R, Myers J, Abella J, Peberdy MA, Bensimhon D, Chase P, et al. The prognostic value of the heart rate response during exercise and recovery in patients with heart failure: Influence of beta-blockade. Int J Cardiol. 2010;138(2):166-73.

6. Freeman JV, Dewey FE, Hadlay DM, Myers J, Froelicher V. Autonomic nervous system interaction with the cardiovascular system during exercise. Prog Cardiovasc Dis. 2006;48(5):342-62.

7. Schwartz P, La Rovete MT, Vanoli E. Autonomic nervous system and sudden cardiac death. Experimental basis and clinical observations for post-myocardial infarction risk stratification. Circulation. 1992;85(1 Suppl):177-91.

8. Maddox T, Ross C, Ho P,Masoudi F,MAgid D, Daugherty SL, etal. The prognostic importance of abnormal heart rate recovery and chronotropic response among exercise treadmill test patients. Am Hear J. 2008;156(4):736-44. 
9. Lahiri MK, Kannankeril PJ, Goldberger JJ. Assessment of autonomic function in cardiovascular disease: physicological basis and prognostic implication. J Am Coll Cardiol. 2008;51(18):1725-33.

10. Ponikowski P, Voors AA, Anker SD, Bueno H, Cleland JGF, Coats AJS, et al 2016 ESC Guidelines for the diagnosis and treatment of acute and chronic heart failure: The Task Force for the diagnosis and treatment of acute and chronic heart failure of the European Society of Cardiology (ESC). Developed with the special contribution of the Heart Failure Association (HFA) of the ESC. Eur Heart J. 2016;37(27):2129-2200.

11. Hasselberg NE, Haugaa KH, Sarvari SI, Gullestad L, Andreassen AK, Smiseth $\mathrm{OA}$, et al. Left ventricular global longitudinal strain is associated with exercise capacity in failing hearts with preserved and reduced ejection fraction. Eur Heart J Cardiovasc Imaging. 2015;16(2):217-24.

12. Rangel I, Gonçalves A, de Sousa C, Almeida PB, Rodrigues J, Macedo F, et al. Global longitudinal strain as a potential prognostic marker in patients with chronic heart failure and systolic dysfunction. Rev Port Cardiol. 2014;33(7-8):403-9.

13. Cameli M, Mondillo S, Righini FM, Lisi M, Dokollari A, Lindqvist P, et al. Left ventricular deformation and myocardial fibrosis in patients with advanced heart failure requiring transplantation. J Card Fail. 2016;22(11):901-7.

14. Lang RM, Badano LP, Mor-Avi V, Afilalo J, Armstrong A, Ernande L, et al. Recommendations for cardiac chamber quantification by echocardiography in adults: an update from the American Society of Echocardiography and the European Association of Cardiovascular Imaging. J Am Soc Echocardiogr. 2015;28(1):1-39

15. Von Elm E, Altman DG, Egger M, Pocock SJ, Gøtzsche PC, Vanderbroucke JP, et al. The Strengthening the Reporting of Observational Studies in
Epidemiology (STROBE) statement: guidelines for reporting observational studies. Epidemiology. 2007;18(6):800-4.

16. Bocchi E, Marcondes-Braga FG, Bacal F, Ferraz AS, Albuquerque D, Rodrigues $\mathrm{D}$, et al. atualização da diretriz brasileira de insuficiência cardíaca crônica - 2012. Arq Bras Cardiol. 2012;98(1 supl. 1):1-33.

17. Faul F, Erdfelder E, Lang AG, Buchner A. G* Power 3: a flexible stattistical power analyses program for the social, behavioral and biomedical sciences. Behav Res Methods. 2007;39(2):175-91.

18. de Groote P, Milleire A, Decoulx E, Nugue O, Guimier P, Ducloux. Kinetics of oxygen consumption during and after exercise in patients with dilated cardiomyopathy. New markers of exercise intolerance with clinical implications. J Am Coll Cardiol. 1996;28(1):168-75.

19. Scrutinio D, Passantino A, Lagioia R, Napoli F, Ricci A, Rizzon P. Percent achieved of predicted peak exercise oxygen uptake and kinetics of recovery of oxygen uptake after exercise for risk stratification in chronic heart failure. Int J Cardiol. 1998;64(2):117-24.

20. Queirós MC, Mendes DE, Ribeiro MA, Mendes M, Rebocho Mal, SeabraGomes R. Recovery kinetics of oxygen uptake after cardiopulmonar exercise test and prognosis in patien0ts with left ventricular dysfunction. Rev Port Cardiol.2002;21(4):383-98.

21. Vivekananthan DP, Blackstone EH, Pothier CE, Lauer MS. Heart rate recovery after exercise is a predictor of mortality, independent of the angiographic severity of coronary disease. J Am Col Cardiol. 2003;42(5):831-8.

22. Cole CR, Blackstone EH, Pashkow FJ, Snader CE, Lauer MS. Heart-rate recovery immediately after exercise as a predictor of mortality. N Engl J Med. 1999;341(18):1351-7. 